\title{
The Quality Monitoring Points of Thin Plaster System on Rock Wool Exterior Wall
}

\author{
Li Changfeng ${ }^{1, a^{*}}$, Lin Pengzhen ${ }^{2, b}$ \\ ${ }^{1}$ Capital Construction Department, Lanzhou Jiaotong University, Lanzhou, China \\ ${ }^{2}$ School of Civil Engineering, Lanzhou Jiaotong University, Lanzhou, China \\ a 824300453@qq.com, bzh_lin@163.com
}

Keywords: Rock wool wall; Plaster system; Quality control

Abstract. The thin plaster system on Rock Wool exterior wall recently becomes more and more popular in real engineering. That there are lots of superior nature in Rock Wool, such as fire-resistance, good stability and so on, have been gradually accepted. Based on the advantage of the fire-protecting performance of exterior wall and possessed the performance of thermal insulation and lightweight, rock wool has widely displaced many forms of external insulation, such as XPS, Phenolic Aldehyde Resin and so on. This paper, combined with construction examples, rendered some analyses focused around how to guarantee the quality effectively.

\section{Introduction}

This project is to build students' apartment (No.2) ofLanzhou Jiaotong University, located in the campus, and possessed the floor area of $19577.86 \mathrm{~m}^{2}$, which is $994 \mathrm{~m}^{2}$ underground and $18583.86 \mathrm{~m}^{2}$ over ground. The basement area of this building is $2934.93 \mathrm{~m}^{2}$, and it is 6 or 7 stories (locally 8 stories over ground and 1 story underground), and the height is $25.5 \mathrm{~m}$. This project is a multi-stories building for living, has the fire resistance rating of class 2 over ground and of class 1 underground. The imitation brick wall of thin plaster system on rock wool has been used to its exterior walls. The basement floor and the separating position between heating area and non-heating area use rock wool to insulate. The insulation project lasts from 20th Jul. to 20th Apr. 2014.

The rock wool in design uses the $5 \mathrm{~cm}$ hydrophobic rock wool insulation board, has a A-grade heat performance, and its thermal conductivity is $0.033 \mathrm{~W} /(\mathrm{m} . \mathrm{k})$. Stone imitation brick effect has been used to decorative surface of exterior wall, and the production method depends on the standard atlas of Gansu province (2012 version).

\section{Monitoring Points of Technical Preparatory Phase}

The Preparation for Construction Plan. It demands that construction drawing should be understand thoroughly, and that construction method of exterior wall and building construction in some special part(opening for windows and doors, awning, angle of rotation, movement joint, roof balustrade, compact mentation of heating area and non-heating area, etc.) should be familiar with. Considering whether it will succeed which depends on Insulation atlas, it should refer to the construction method of atlas optimization of thermal insulation if it will not. Combining the demand of the rules for thermal insulation of exterior wall and the code for construction and acceptance, the plan for thermal insulation of exterior wall should be compiled and the review process should be perfected. After seriously examining and verifying by related party, construction of model wall can be carried out after subjected to approval.

Technical Preparation. Concerned personnel involved in the construction ought to study carefully national codes and local rules (of Tianjin, north city in China) related in insulation wall, mainly list the key control points and monitor it. Concerned personnel involved in the construction are supposed to be familiar with construction drawings, and take necessary measures to cope with the problems existed in the drawings. To make the construction drawings of joint detail and heat channel and other part based on the demands in the 
construction paper and atlas, and to give the real in-tensions in the form of writing to operating workers. Depends on the characteristics of this project, the technical intensions and measures of construction should be compiled in time, and approval procedures should be went through, and thus give the technical intensions and measures in the form of writing to technical workers. And it should be equipped with specially assigned person to gather and arrange technical materials. It also should be organized trainings to improve workers to familiar with construction techniques of thermal insulation of exterior wall, and organized pre-job training, and organize the workers to watch construction videos of thermal insulation of exterior wall, and take examination.

Technical Preparation. Concerned personnel involved in the construction ought to study carefully national codes and local rules (of Tianjin, north city in China) related in insulation wall, mainly list the key control points and monitor it. Concerned personnel involved in the construction are supposed to be familiar with construction drawings, and take necessary measures to cope with the problems existed in the drawings. To make the construction drawings of joint detail and heat channel and other part based on the demands in the construction paper and atlas, and to give the real in-tensions in the form of writing to operating workers. Depends on the characteristics of this project, the technical intensions and measures of construction should be compiled in time, and approval procedures should be went through, and thus give the technical intensions and measures in the form of writing to technical workers. And it should be equipped with specially assigned person to gather and arrange technical materials. It also should be organized trainings to improve workers to familiar with construction techniques of thermal insulation of exterior wall, and organized pre-job training, and organize the workers to watch construction videos of thermal insulation of exterior wall, and take examination. Monitoring Points of Controlling the Raw Materials. It must be no doubt that whether the raw materials are good or not is the key condition of quality in any products. The main material of exterior wall of rock wool mainly includes: rock wool, Adhesive mortar, hold fast, Fiberglass Mesh, plastering mortar, etc. and, of course, the most important part is the rock wool panel. Nowadays, as the rise of demand in market, the enterprises producing rock wool have a big augment. Among them are lots of company with good reputation, and, on the other hand, also of illegal company having a bad quality and pursuing interest only, whose products have a huge quality differences. Till now, the demand in our country for quality of rock wall used to thermal insulation for exterior wall exceeds it in Europe. And rare products can pass the test in each indicator. Some of companies' products samples for testing are very different from real products. So, we should select the products from the enterprises in big brand and good reputation, examine whether the certificate of products, delivery inspection report, quality guarantee, test report within the validity period and other testing report in each performance is Complete and effective. And visually examine appearance of every raw materials, and that rock wool broken and twisted and rock wool panel that not able to meet the standard requirements in terms of standard, dimension and thickness should be resolutely cleared. Besides viewing the inspection reports of type, re-inspection report of some projects carried out should be compared and re-inspection works should be made well. The re-inspection works are supposed to depends on the standard Rock Wool Products for Exterior Insulation (GB/T25975-2010), and to focus on compared with the indicators such as tensile strength, compressive strength and Short term water absorption, which is very uncertain in the products produced by many small enterprises. Other materials should check carefully the conformity between identification and certificate, inspection reports of type. For the materials that should be re-inspected, such as adhesive for thermal insulation of exterior wall, interface treating mortar, anti-crack mortar, enhanced network, etc., the supervisor side should urge the construction side to take necessary evidential sampling and re-inspection strictly according to the request. The material of same variety and type produced by same company should be took a set of samples at least to do re-inspection. Whether the materials that make-up-in-situ, such as mortar, adhesive, etc., is made-up according to the design requirement and products direction. Before using the material of wall insulation, it should be taken checking and accepting works and sampling re-inspection, the design and current related standards of construction materials. 


\section{Monitoring Points of Controlling Quality in Process of Construction}

Model Approach. By material retest qualified, according to the existed plan of construction, System component materials have been used to make insulation wall. The model wall reflects the paste method of insulation panel, how to control the paste area, the treatment method of Slab joint dislocation and of feminine elements angle, the mode and number of anchor bolts, the proportioning and control of adhesive and of the surface layer of mortar, and how to control defect of Paste base, etc. After the process of construction of model wall, construction side, combined with other parties, such as designing, supervisor, and builder, etc., should take on-sites work examination, and make model record if it is up to standard, and organize operating workers to observe and study before constructing, and make model real intensions well, and strictly control quality in the process of construction in accordance with the model. Air-condition panel, the side wall of windows and other special parts should be did as the same method.

System Structure of Insulation for Exterior Wall. The system structure of insulation for exterior wall is shown in Table 1.

Table 1. Details of Insulation Structure of Exterior Wall

\begin{tabular}{ccc}
$\begin{array}{c}\text { Basic structure of } \\
\text { system }\end{array}$ & composite materials \\
\hline $\begin{array}{c}\text { Basic unit wall(1) } \\
\text { Bonding layer(2) }\end{array}$ & Bonding agent for rock wool wall or masonry wall \\
\hline Boundary layer(3) & Bonding agent for rock wool \\
\hline $\begin{array}{l}\text { Insulating layer(4) } \\
\text { Boundary layer(5) }\end{array}$ & Anchor \\
\hline Ponnecting piece(6) & Base coat + Double alkali resistant fiberglass \\
mesh + Elastic primer
\end{tabular}

Monitoring Points of Controlling Quality before Pasting Rock Wool Panel. The monitoring points of controlling quality should be done as following processes before stage of pasting rock wool panel:

(a) Inspection of Wall Body. The surface of troweling layer of exterior wall should keep dry and clean. Smoothness and verticality should reach the requirements of accepting rules. Expended cement mortar shall be used to the bolt hole and other hole, and the surface of the opening of hole should be pasted the water-proof paint twice. Whether this step has been done well or not is the base of aesthetic measure after the process of construction of exterior wall. However, this process in many projects is so neglected that the planeness of decorative face of exterior wall couldn't reach the standards or generated bad ripples. In this project, by a series of strict inspection and several corrections, the final effect of decoration of exterior wall is relatively good.

(b) Preparation of Mortar. Mortar in the use of construction can be laid special use adhesive and base coat on surface, should be stirred by hand-held electric mixer, and the proportion by weight of adhesive is 4 to 1 (powder to water), and the process of stirring should continue for $5 \mathrm{~min}$ at least, by watering when stirring, and would be thorough and even, and have a moderate density and certain viscosity. Mortar should stand for $5 \mathrm{~min}$ when the process of stirring finished, and should stir it again when it would be used. The mortar stirred should be used up within $1 \mathrm{~h}$ [4].

(c) Packed-up Mesh in Pre-glued Panel End. It should paste the Packed-up Mesh to roof overhang and balcony and other parts. Paste the $150 \mathrm{~mm}$ part of not less than $250 \mathrm{~mm}$ wide net cloth to the base surface 
by using special use adhesive, whose thick-ness should not be more than $2 \mathrm{~mm}$, and then rest of net cloth can be turned over when pasting rock wool panel.

Monitoring Points of Controlling Quality in Pasting Rock Wool Panel. The monitoring points of controlling quality should be done as following processes in stage of pasting rock wool panel:

(a) When to paste rock wool panel, slab joint should be tight, adjoined panel should be even, gap in panels should be less than $2 \mathrm{~mm}$, elevation difference between panels should be less than $1 \mathrm{~mm}$, and the surface of the gap in panels should be filled up and made even by using Foamed Polyurethane. Basic content of strip method is that to paste the pre-pared adhesive along the length direction by using special use stainless steel and serrated trowel to rock wool panel, which the area of pasting should be more than $70 \%$.

(b) Mesh should be packed up from the corner part to whole board, and should be packed-up by Alkali resistant fiberglass mesh when coming across the end position of the opening for windows and doors, plinth, balcony, rain shed and other systems, and the position of needing to stop system, that is to paste pre-post mesh on the basic unit wall by using Polymer adhesive, and the width of pasting in the part of packed-up should be more than $100 \mathrm{~mm}$ and lap joint could not exist in packed-up mesh itself. To prevent water leakage of windows, it should put Straight Slot round the windows and between windows frames, which is, after fixed and been accepted, to put Polyurethane foam, to plug polyethylene foam bar, and to pour Refractory sealant in the straight slot by construction party of exterior windows.

(c) Fixed Belt of Metal. Putting the Fixed belt of Metal up to the gable that have a big area of insulation layer is to mainly resist Negative air pressure. Fixed belt of Metal, also known as metal bracket, whose metal material should be took oxidation treatment which need to punch earlier and be took anodic oxidation treatment later. The thickness of oxide film should be more than $10 \mathrm{um}$, and oxidation treatment of the whole bracket should be well-distributed and even. The surface of sectional material should be clean, and there should be no flaw, peeling, corrosion, bubble, and falling of oxide film, etc. And there should be no rag on the punching hole and the edge of sectional material, and no aperture on two ends and edge of bracket.

Monitoring Points of Controlling Quality for Cons truction of Imitation-brick-stone Paint. Monitoring points of controlling quality for construction of imitation-brick-stone paint should be done as following processes:

(a) Firstly, we should check the verticality, plane-ness, whether the part of joint is straight or not, and whether the dividing strip is even and smooth or not. These conditions, such as losing, pulverizing, pitting surface, flaw, and swelling, etc., cannot be appeared in the surface of base layer. The metal elements and screws that exposed from base layer should be taken stain-proofing treatment.

(b) Putty. This project adopted the putty that only used for exterior wall, and mix it with water to made preparation. And then put this putty preparation onto base surface by using trowel. Each layer of putty on surface should be controlled into $1 \mathrm{~mm}$ or so. After twice process, the total thickness should be con-trolled into within $2 \mathrm{~mm}$, otherwise it could generate some negative effect.

(c) Painting Base Coat that used for Alkali-resistant. In 48 hours of the construction putty has completed, the process of brushing base coat can be undertaken. The PH level of base surface should be less than 10, and water content should be less $10 \%$.

(d) Snap-line divisions and Paste Wove Paper. According to the dimensions of Imitation brick and width of joint from design to choose wove paper and paste it along the snap line, which is demanded horizontal and vertical and accurate.

\section{Conclusion}

This paper, combined with a project instance of thin plaster imitation brick wall of exterior insulation by rock wool that finished recently, showed some analyses on aspects of characteristics of rock wool, quality problems occurred more easily, the point of quality controlling, etc., expected to capture builders and supervisors to focus on the quality of thin plaster Imitation brick wall of exterior insulation by rock wool, and 
to improve overall quality levels and ensure investment effect. As the thin plaster system of exterior insulation by rock wool has been used more widely, according to the brief description in this paper, we hope it could generate certain positive effect on construction quality. Keeping and making earnestly the control of construction quality well is a systematic work. So long as preparation is done thoroughly, raw material is controlled highly, the process of construction is conducted strictly, and a durable and beautiful engineering of exterior wall could be made absolutely.

\section{References}

[1] GB50411 - 2007, Code for acceptance of construction quality of building energy saving engineering.

[2] GB/T 25975 - 2010, Rock wool products for exterior insulation and finish system.

[3] Li.X.M., Cao.Y.Z., The performance and application of rock wool insulation of exterior wall, Liaoning building materials, 2 (2011): 41-45.

[4] Wang,Q.J., Interpretation of "Rock wool products for exterior insulation and finish system", Innovation and building energy-saving wall, 8 (2011): 45-47.

[5] Yan,F., Yan. S.L., Application of rock wool in external thermal insulation system, Shanghai Coatings, 6 (2011): 20-22. 